\title{
Mid-sagittal section of the fetal face: Still a showstopper
}

Sir,

We allude to the interesting article titled, 'Intracranial translucency as a sonographic marker for detecting open spina bifida at $11-13^{+6}$ weeks scan: Our experience by Teegala et al. ${ }^{[1]}$ The authors have clearly illustrated the significance of the obliteration of intracranial translucency (IT) as a marker for open spinal dysraphism (OSD) in the first trimester. Evaluation of the mid-sagittal plane of the fetal face is an integral part of every first trimester scan between 11 and $13^{+6}$ weeks. As the time spent on each scan is an important consideration in clinical practice, evaluation of IT in the same mid-sagittal plane gives a rich dividend of early detection of an OSD at no extra cost of time. However, there are instances when IT is difficult to assess, as is the case in this study as well.

In a recent study, Ramkrishna et al. proposed a novel marker for detection of OSD in the first trimester, namely the maxillo-occipital line in the mid-sagittal plane. ${ }^{[2]}$ The maxillo-occipital line is a straight line drawn along the superior border of the maxilla that touches the occipital bone posteriorly. The authors observed that the junction of the thalamus with the midbrain was above this maxillo-occipital line in normal fetuses and below this line in the fetuses with open spina bifida. This can be attributed to the descent of the brainstem in open spina bifida due to the egress of the cerebrospinal fluid through the spinal defect. The observation is illustrated in a normal fetus [Figure 1] and a fetus with lumbosacral myeloschisis [Figure 2]. These findings are also evident in the cases shown in the article by Teegala ML et al. Assessment of the case in this study in which the IT was not clear using the maxillo-occipital line may be enlightening.

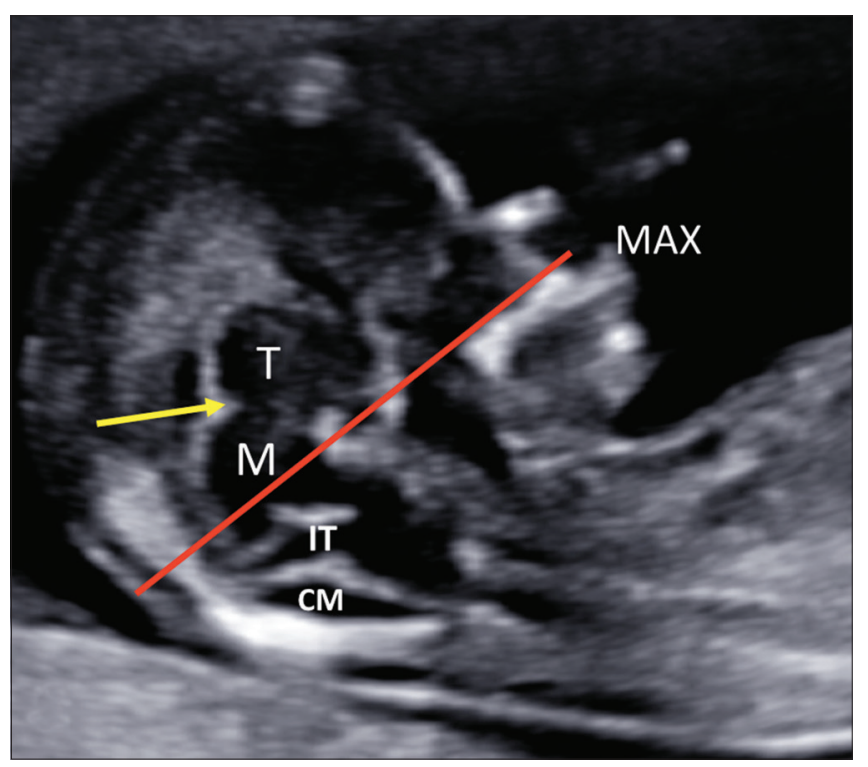

Figure 1: Mid-sagittal section of the face in a normal fetus at $12^{+4}$ weeks. The maxillo-occipital line (red line) is drawn along the superior border of the maxilla (MAX) touching the occipital bone posteriorly. The junction (arrow) of the thalamus $(\mathrm{T})$ with the midbrain $(\mathrm{M})$ is above this line. Intracranial translucency (IT); Cisterna magna (CM) 


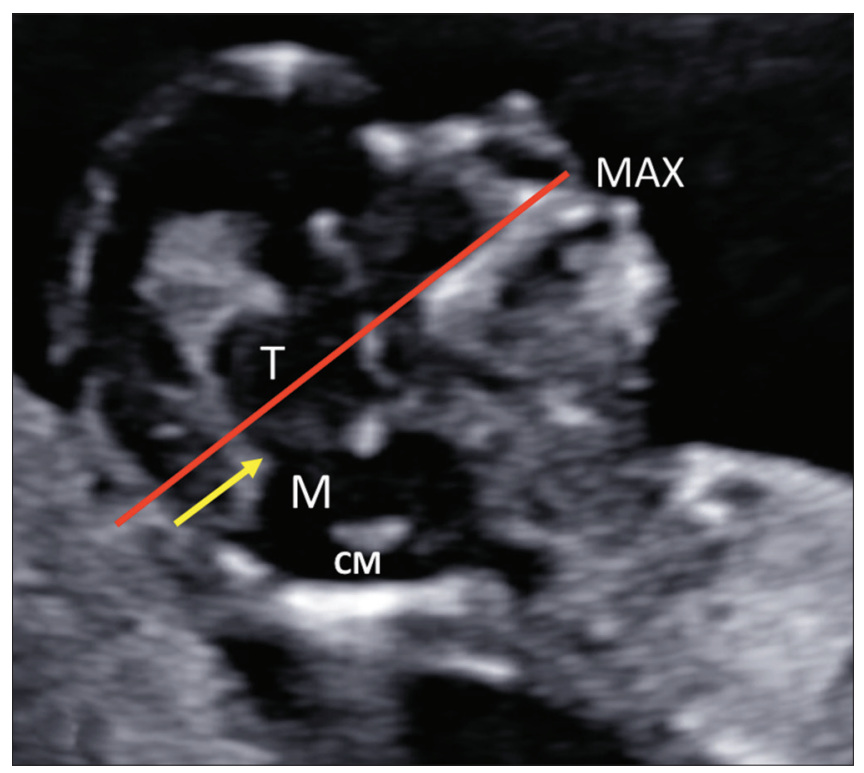

Figure 2: Mid-sagittal section of the face in a fetus with open spina bifida at $12^{+3}$ weeks. The maxilla-occipital line (red line) is drawn along the superior border of the maxilla (MAX). The junction (arrow) of the thalamus $(T)$ with the midbrain $(M)$ is below this line. The intracranial translucency is obliterated. Cisterna magna $(\mathrm{CM})$

In conclusion, obliteration of IT (fourth ventricle) is a strong marker for OSD in the first trimester. The novel marker, namely the maxillo-occipital line, which is a pointer of brainstem descent in OSD may aid in enhancing the operator's degree of confidence in case IT is not clear. Although the mid-sagittal section of the fetal face made its debut on the runway more than two decades ago to measure nuchal translucency, it continues to be a showstopper revealing new sonographic markers of fetal anomalies.

Financial support and sponsorship

Nil.

\section{Conflicts of interest}

There are no conflicts of interest.

\section{Divya Singh, Ladbans Kaur \\ Department of Radiodiagnosis Prime Imaging and Prenatal Diagnostics, Chandigarh, India E-mail: docdivyas@yahoo.co.in}

\section{References}

1. Teegala ML, Vinayak DG. Intracranial translucency as a sonographic marker for detecting open spina bifida at $11-13^{+6}$ weeks scan: Our experience. Indian J Radiol Imaging 2017;27:427-31.

2. Ramkrishna J, Araujo Junior E, White N, da Silva Costa F, Meagher S. P09.11: Maxillo-occipital line: A sonographic marker for the screening of open spina bifida in the first trimester. Ultrasound Obstet Gynecol 2017;50:184.

This is an open access journal, and articles are distributed under the terms of the Creative Commons Attribution-NonCommercial-ShareAlike 4.0 License, which allows others to remix, tweak, and build upon the work non-commercially, as long as appropriate credit is given and the new creations are licensed under the identical terms.

\begin{tabular}{|l|l|}
\hline \multicolumn{2}{|c|}{ Access this article online } \\
\hline Quick Response Code: & \\
\hline & Website: \\
\hline & www.ijri.org \\
& DOl: \\
\hline
\end{tabular}

Cite this article as: Singh D, Kaur L. Mid-sagittal section of the fetal face: Still a showstopper. Indian J Radiol Imaging 2018;28:376-7.

() 2018 Indian Journal of Radiology and Imaging | Published by Wolters Kluwer - Medknow 